\title{
Competência em informação: uma abordagem sobre o arquivista $^{1}$
}

\author{
Renata Ventura \\ Eva Cristina Leite da Silva \\ Elizete Vieira Vitorino \\ Universidade Federal de Santa Catarina - UFSC, Brasil
}

REVIEW

\begin{abstract}
Resumo
Objetivo. Analisa possíveis conexões entre a competência em informação, o arquivista e o arquivo. As atribuições do arquivista foram estudadas, a fim de identificar quais os vínculos com a competência em informação, tendo como base o que se apresenta na bibliografia arquivística e de competência em informação.

Método. A pesquisa tem por finalidade ser básica, está caracterizada em relação ao objetivo como exploratória, apresenta abordagem qualitativa, e utiliza a técnica bibliográfica.

Resultados. Os resultados apresentam a competência dos profissionais da informação, definem a competência em informação, tratam da competência em informação do arquivista e da dimensão política evidenciada na relação arquivista e arquivo. Conclui que o arquivista é um profissional competente em informação e suas atribuições intensificam essa competência. Com relação ao arquivo, esse ambiente auxilia no desenvolvimento da dimensão política da competência em informação do arquivista, já que permite o acesso às informações documentais e o exercício da cidadania.
\end{abstract}

Palavras-chave

Arquivo; Competência dos profissionais da informação; Competência em informação; Competência em informação do arquivista; Dimensão política; Função educativa do arquivista

\section{Information literacy: an approach about archivist}

\begin{abstract}
Objective. It analyzes possible connections between information literacy, the archivist and the archive. The assignments of the archivist were studied in order to identify the links with information literacy, based on what is presented in the archives administration bibliography and information literacy.

Method. The research aims to be basic, is characterized in relation to the objective as exploratory, presents a qualitative approach, and uses the bibliographic technique.

Results. The results present the competence of the information professionals, define the information literacy, the competence in information of the archivist and the political dimension in the relation archivist and archive. It concludes that the archivist is a competent information professional and his assignments intensify this competence. Regarding the archive, this environment assists in the development of the political dimension of the information literacy of the archivist, since it allows access to documentary information and the exercise of citizenship.
\end{abstract}

Keywords

Archive; Competence of Information Professionals; Educational Function of the Archivist; Information Literacy; Information Literacy of Archivist; Political Dimension

\footnotetext{
1 O presente trabalho foi realizado com apoio da Coordenação de Aperfeiçoamento de Pessoal de Nível Superior - Brasil (CAPES) - Código de Financiamento 001.
} 


\section{Introdução}

O emergir de demandas no âmbito dos estudos sociais requer uma autoavaliação das práticas com relação ao campo de atuação profissional. Neste contexto, delineia-se aqui o arquivista, enquanto profissional responsável pela organização, preservação e acesso da informação arquivística, perpassado por transformações dos novos meios de comunicabilidade (produção, representação, recuperação, disponibilização, entre outros). 0 atendimento das demandas de um amplo e diverso grupo de usuários exige que este profissional rompa com determinados modelos de atuação, deixe de operar como custodiador de documentos, e passe a ter um comportamento proativo com relação ao acesso informacional. Nota-se então que o trabalho arquivístico se reveste de um interesse que ultrapassa o tradicional trabalho técnico de organização e conservação das fontes documentais.

Esse novo paradigma social impacta na atuação do arquivista, que a partir de então direciona suas ações também para os processos de recuperação e disseminação de informações, os quais estão diretamente vinculados com as funções da gestão documental arquivística: produção, aquisição, preservação, classificação, avaliação, descrição e difusão. Orelo (2013) ressalta que o atual contexto informacional requer profissionais preparados para trabalhar com o fluxo e os recursos informacionais, bem como, tratá-los de forma a tornar possível a recuperação e o uso da informação.

A competência em informação proporciona ao arquivista o desenvolvimento das habilidades necessárias para localização, análise e uso das informações de forma a satisfazer suas necessidades. Essa competência complementa o desenvolvimento das atividades profissionais, pois "[...] o trabalho arquivístico, em si mesmo, já implica a pesquisa. Atividades como avaliação, descrição, estudos de usuários, entre outras, pressupõe uma abordagem investigativa" (JARDIM, 1998, p. 7). O que pode evidenciar que a competência em informação, justapõem a formação e a atuação do arquivista.

Por ser o arquivista um dos profissionais que trabalha com a informação e, além disso, suas atribuições demandarem pelo desenvolvimento da competência em informação, questiona-se: na formação e na prática do arquivista apresenta-se a competência em informação? Dessa forma, tem-se como objetivo geral analisar a competência em informação sob a perspectiva da atuação do arquivista. Para atingi-lo, busca-se na literatura da área de ciências sociais aplicadas no que se refere à Arquivologia, Biblioteconomia e Ciência da Informação as discussões referentes a: identificar a competência dos profissionais da informação; definir a competência em informação e as suas dimensões técnica, estética, ética e política; investigar o que caracteriza a competência em informação do arquivista; e aprofundar o entendimento da competência em informação desse profissional com destaque para a dimensão política, no que se refere à função educativa que se apresenta.

A relevância do tema se pauta nas discussões a respeito dos conhecimentos do arquivista perpassados pela competência em informação. Além disso, possibilita a pesquisa de literatura referente ao tema e uma conscientização com relação às exigências e demandas do trabalho arquivístico, mostrando que vão além das atividades "internas" de gestão documental arquivística, e que há a necessidade de diálogos profícuos com a sociedade e com os usuários. Dessa forma aproxima-se a Arquivologia da Ciência da Informação $(\mathrm{Cl})$, tendo em vista que Borko (1968) definiu que a Cl preocupa-se com o comportamento informacional, considerando seus fluxos e significados para promoção do acesso e uso da informação. Por meio disso se estimula o contato e acesso às informações provenientes dos arquivos.

Para tanto, nesse estudo buscou-se a ampliação do conhecimento sobre a competência em informação no âmbito da Arquivologia, verificando os desdobramentos em relação ao arquivista. Com relação a sua finalidade, essa pesquisa apresenta-se como básica ou pura, sendo assim, optando pela forma teórica buscam-se novos conhecimentos sobre o tema abordado (COOPER; SCHINDLER, 2016). A necessidade de identificar as características da competência em informação do arquivista torna a pesquisa, quanto aos objetivos, exploratória. Malhotra (2012, p. 59) destaca que "[...] o objetivo da pesquisa exploratória é explorar ou fazer uma busca em um problema ou em uma situação a fim de oferecer informações e maior compreensão [...]".

Além disso, considera-se que esta pesquisa apresenta abordagem qualitativa, já que procura compreender as características que unem o arquivista e a competência em informação. Esse tipo de pesquisa destaca-se por ser a "[...] tentativa de uma compreensão detalhada dos significados e características situacionais apresentadas [...], 
em lugar da produção de medidas quantitativas de características ou comportamentos" (RICHARDSON; PERES, 2012, p. 90).

Caracteriza-se também por ser bibliográfica, sendo necessário "[...] destacar que ela é sempre realizada para fundamentar teoricamente o objeto de estudo, contribuindo com elementos que subsidiam a análise futura dos dados obtidos" (LIMA; MIOTO, 2007, p. 44). A bibliografia existente é utilizada como principal fonte de estudo para a identificação da competência em informação do arquivista.

\section{Competência dos profissionais da informação}

O desenvolvimento das atividades profissionais exige habilidades relacionadas a cada área do conhecimento técnico, para que assim se tenha uma atuação adequada em relação as suas atribuições. Ao pensar nestes aspectos e nas mudanças do contexto informacional, faz-se necessário tratar da competência dos profissionais que trabalham com a informação.

A informação necessita de tratamentos específicos, como forma de atender as necessidades do ambiente que está inserida, bem como dos seus usuários. Dessa forma, cabe destacar que:

\footnotetext{
[...] não há um perfil de profissional da informação ou do conhecimento único. É impossível encontrar, em apenas uma profissão ou em um determinado perfil, a síntese de atividades que compreenda todas as facetas da informação e do conhecimento necessárias para o desenvolvimento das atividades de uma organização ou do desenvolvimento de uma sociedade (TARAPANOFF; SUAIDEN; OLIVEIRA, 2002, p. 8).
}

Conforme o exposto, o trabalho com informação não se restringe a um determinado profissional que atue em uma unidade de informação específica. A informação está presente em múltiplos suportes e formatos, o que demanda conhecimentos e técnicas adequadas para sua gestão. Porém, espera-se que esses profissionais saibam acessar, recuperar e analisar as informações e suas fontes, e, além disso, consigam desenvolver produtos e prestar serviços relacionados à informação (FERREIRA, 2003).

Ao identificar que os profissionais que trabalham com a informação possuem especificidades de acordo com sua área do conhecimento e seus objetivos, fica evidente que não há um conjunto único de habilidades, conhecimentos, comportamentos, valores e atitudes que constituem os profissionais da informação. Nesta perspectiva, o termo competência refere-se a algo que:

\footnotetext{
[...] pode portanto ser demonstrada e avaliada, e é eminentemente situacional, ou seja, a competência actua em função das características da situação, mas também da representação que o agente faz da situação. Descrever uma competência consiste em identificar e objectivar o que é necessário saber para se ser actuante num domínio de atividade (CORREIA, 2003, p. 13).
}

Portanto, o profissional competente é capaz de atuar nas suas áreas de interesse e, por meio de seus conhecimentos, juntamente com a análise do contexto, determinar o que é necessário fazer. Por isso, pode-se entender que o profissional da informação competente, atua adequadamente na atividade que lhe couber.

Paralelamente a isso, cabe compreender que habilidades e competência são distintas. Nesse sentido, vale destacar que a habilidade

\footnotetext{
[...] indica facilidade em lidar com um tipo de informação e para que se transforme em competência será necessário investimento em experiências de aprendizagem. No entanto, se não houver investimento, não haverá competência, mesmo que a pessoa tenha habilidade em determinada área (PRIMI et al,2001, p. 155).
}

Apesar das diferenças, habilidade e competência, são características conexas. Então as habilidades para atendimento das atuais necessidades, requerem uma mudança na formação enquanto profissional. Por isso, além de dominar as técnicas referentes à gestão do ciclo informacional que compreende a criação, uso, organização e disseminação da informação, o profissional da informação precisa também saber atuar como 
mediador entre as fontes de informação e seus interessados (BELLUZZO, 2011). O que se destaca é que não basta somente guardar e tratar adequadamente a informação é preciso saber permitir o acesso a elas.

Partindo dessas premissas com relação aos profissionais da informação, o Conselho Europeu das Associações de Informação e Documentação (ECIA) desenvolveu um documento onde apresenta a competência dos profissionais europeus de informação e documentação a partir de cinco grupos: informação; tecnologia; comunicação; gestão; e outros saberes (domínio sobre outra área de conhecimento, como por exemplo, relacionada ao conteúdo dos documentos ou com as atividades do produtor do acervo) (ECIA, 2005). Os quatro primeiros grupos correspondem àquilo que é comum aos diversos profissionais, já o último grupo está relacionado à formação e atuação profissional. Cabe destacar que os desenvolvedores do documento do ECIA entendem que o grupo referente à informação '[...] constitui o 'coração da profissão' de informaçãodocumentação, quer dizer os domínios em que não é permitido que um profissional não seja competente, ainda que a um nível básico" (ECIA, 2005, p. 11).

A seguir é possível observar os grupos mencionados acima e uma breve descrição de cada:

Figura 1. Grupos da Competência dos Profissionais da Informação e Documentação

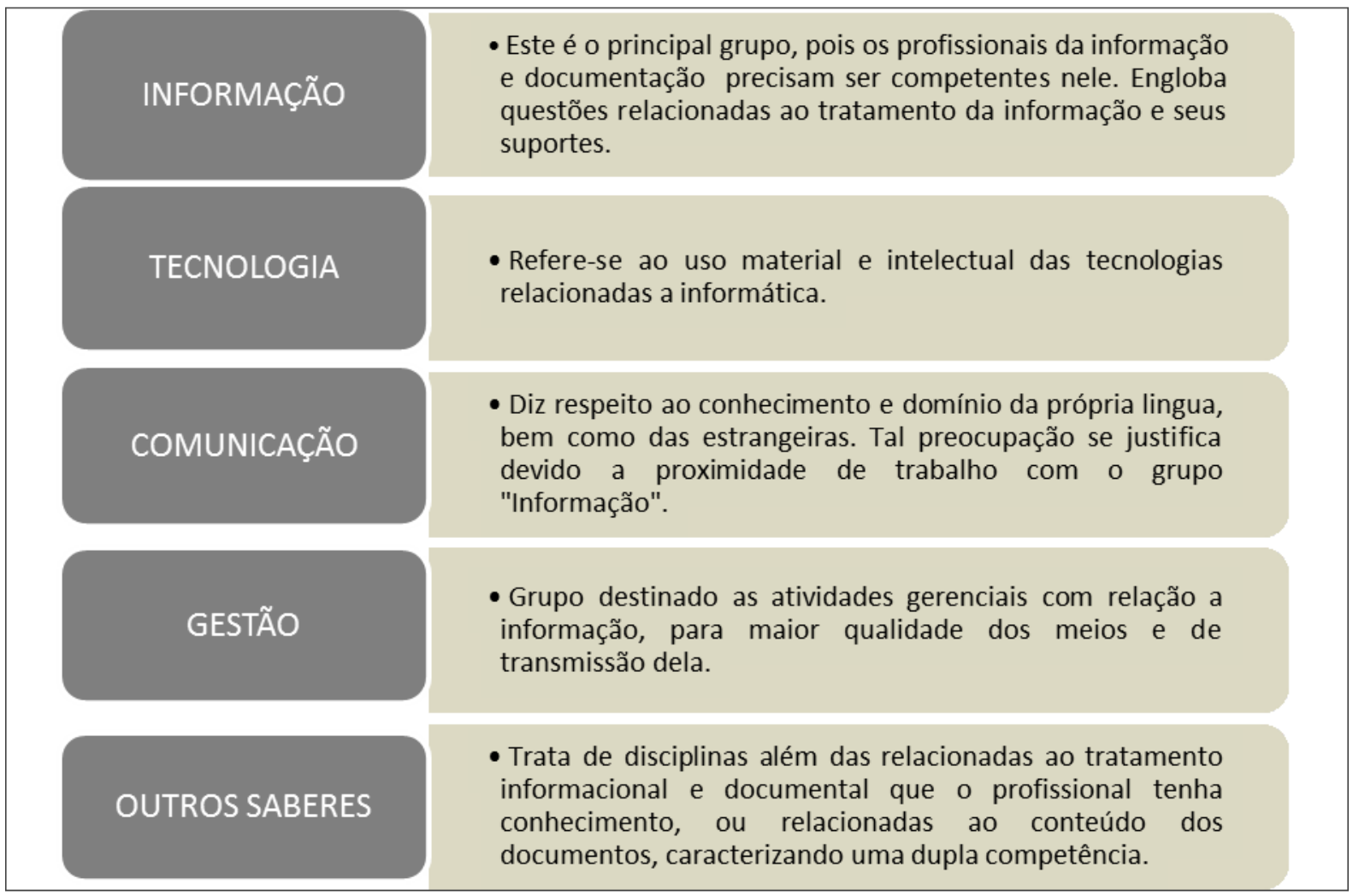

Fonte: Elaborada pelas autoras (2016), baseado no ECIA (2005)

Após análise percebe-se que são grupos complementares, onde cada qual expande a competência em informação para diversos fatores que estão diretamente relacionados à realidade informacional e documental. Além disso, Correia (2003) destaca que cada grupo possui quatro níveis de domínio dessa competência, sendo elas: o conhecimento da atividade; o saber fazer; o conhecimento e domínio das ferramentas; e o entendimento dos métodos. Esses domínios estão correlacionados com a construção do conhecimento de cada profissional, e são partes de um processo: compreensões e aprofundamentos de um todo. Com isso, percebe-se que existem diferentes níveis para ser competente em qualquer dos grupos apresentados pelo ECIA (2005), ou seja, nem todos os profissionais da informação dominarão igualmente esses grupos de competência.

Sob outra perspectiva, a competência dos profissionais da informação, também está caracterizada na Classificação Brasileira de Ocupações (CBO) elaborado pelo Ministério do Trabalho e Emprego (MTE). Porém cabe destacar, que a família dos Profissionais da Informação, não apresenta uma descrição completa desses profissionais, já que, por exemplo, observa-se a falta do arquivista nesse grupo que consta o bibliotecário, 
documentalista e o analista de informações. De qualquer forma, a competência dos profissionais da informação apresenta-se em quatorze itens que compreendem:

Manter-se atualizado; Liderar equipes; Trabalhar em equipe e em rede; Demonstrar capacidade de análise e síntese; Demonstrar conhecimento de outros idiomas; Demonstrar capacidade de comunicação; Demonstrar capacidade de negociação; Agir com ética; Demonstrar senso de organização; Demonstrar capacidade empreendedora; Demonstrar raciocínio lógico; Demonstrar capacidade de concentração; Demonstrar pró-atividade; Demonstrar criatividade (MINISTÉRIO DO TRABALHO E EMPREGO, [2016?], online).

Percebe-se que a competência apresentada na CBO está voltada para um contexto de exigências organizacionais, se comparado com o apresentado pelo ECIA (2005). Por outro lado, o documento da CBO (MTE, [2016?]) pode ser correlacionado aos quatro grupos da competência dos profissionais da informação e documentação defendidos pelo ECIA (Tabela 1). Sendo assim, verifica-se que há uma consonância no que se deseja da atuação dos profissionais da informação. Além disso, Faria et al. (2005, p. 28) também ressaltam essa proximidade entre a competência definida pelos europeus e a da realidade brasileira, entendendo que relacionado a isso está a propagação das exigências da sociedade do conhecimento por diversos ambientes.

Tabela 1. Competência e áreas de atividade da CBO e a competência e aptidões correspondentes do ECIA

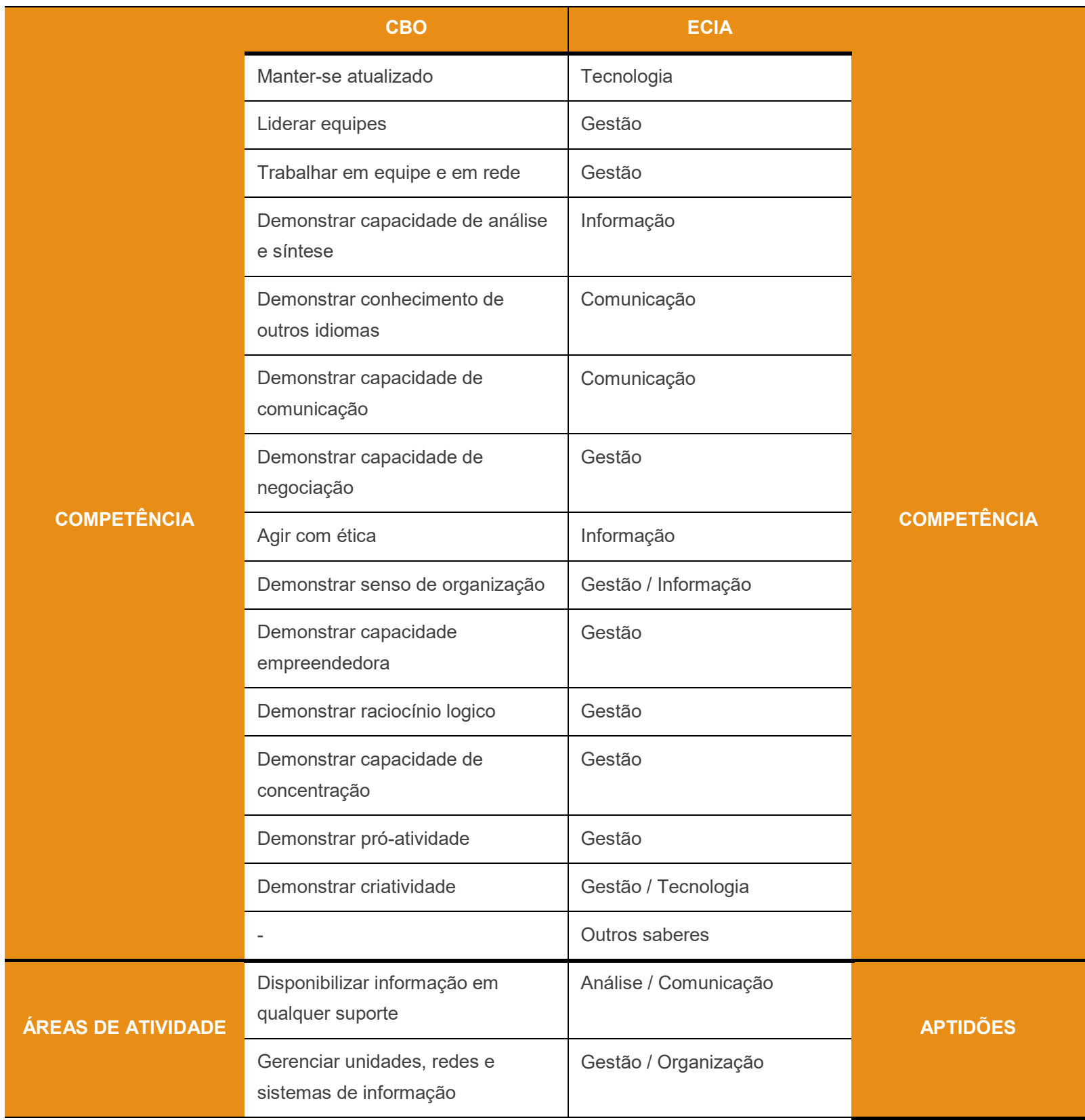




\begin{tabular}{l|l}
\hline $\begin{array}{l}\text { Tratar tecnicamente recursos } \\
\text { informacionais }\end{array}$ & Análise \\
\hline $\begin{array}{l}\text { Desenvolver recursos } \\
\text { informacionais }\end{array}$ & Análise \\
\hline Disseminar informação & Relacionamento/Organização \\
\hline Desenvolver estudos e pesquisas & Pesquisa \\
\hline $\begin{array}{l}\text { Prestar serviços de assessoria e } \\
\text { consultoria }\end{array}$ & Relacionamento/Organização \\
\hline Realizar difusão cultural & Relacionamento/Organização \\
\hline Desenvolver ações educativas & Relacionamento/Organização \\
\hline $\begin{array}{l}\text { Demonstrar competências } \\
\text { pessoais }\end{array}$ & Relacionamento/Organização \\
\hline
\end{tabular}

Fonte: Elaborado pelas autoras (2016) baseado MTE ([2016?]) e ECIA (2005).

A tabela 1 sintetiza e correlaciona os grupos de competência, áreas de atividades e aptidões que são apresentados pela CBO (MTE, [2016?]) e ECIA (2005). Como o ECIA optou por grandes grupos procurou-se identificar no material proposto pela CBO quais atividades são relacionadas a esses grupos. Do grupo de competência referente "Outros saberes" nada foi identificado, já que depende de conhecimentos específicos de cada profissional. Optou-se por comparar as aptidões com as áreas de interesse por entender que as aptidões determinam as áreas onde esse profissional pode atuar e, por isso possuem relação causal.

Com base no exposto, cabe destacar que a atuação dos profissionais da informação engloba o conjunto das técnicas, das teorias, dos valores, dos comportamentos individuais e coletivos. Diz-se isso, pois, percebe-se uma preocupação com o entorno desse profissional, evidenciando relações com os grupos de trabalho, bem como as questões éticas e tecnológicas. Esta última como um dos itens influenciadores da demanda por atualização constante por parte desses profissionais, presumindo o domínio de novos conhecimentos e das ferramentas de tecnologia da informação e comunicação.

As ferramentas tecnológicas facilitam a comunicação, por outro lado aumentam a quantidade de informações disponíveis e compartilhadas. Essa realidade requer uma atenção especial por parte dos profissionais da informação, já que impacta diretamente no seu trabalho. Nesse mesmo contexto, Silva e Ribeiro (2004, p.1) afirmam que

\footnotetext{
[...] o envolvimento da sociedade pelo fenômeno da informação, em plena simbiose com as Tecnologias da Informação e da Comunicação (TIC), determina comportamentos, atitudes e fomenta práticas de organização e pesquisa da informação, [...] que não podem ser alheias ao perfil do profissional que, forçosamente, terá de substituir o tradicional bibliotecário / arquivista / documentalista.
}

Dessa forma, percebe-se que a competência profissional também está em constante mudança, pois as atividades se alteram conforme se apresentam novas necessidades com relação à informação e à comunicação. Sendo assim, daquilo que foi apresentado até aqui sobre a competência dos profissionais da informação cabe destacar o uso da noção de competência em informação, cujo significado, engloba, noutra perspectiva, aquilo que está apresentado nos documentos do ECIA (2005) e da CBO (MTE, [2016?]), numa forma de "guardachuva".

A competência em informação perpassa o desenvolvimento da competência que caracteriza o profissional da informação. Para que ele seja competente e se desenvolva no que tange as suas aptidões e áreas de atividade, é necessária a competência em informação, a qual vai possibilitar a identificação, análise, seleção e uso do objeto informacional. 


\subsection{Competência em informação}

Os profissionais da informação por atuarem no processo que compreende desde a produção até a recuperação das informações necessitam desenvolver uma competência específica para a realização dessas atividades. 0 grande volume informacional requer uma competência "guarda-chuva" para identificar quais habilidades, conhecimentos, comportamentos, valores e atitudes devem ser mobilizados para a identificação de oportunidades e para a solução de problemas de informação, por isso os profissionais competentes em informação passam a desempenhar o papel de mediadores e também instrutores no uso de informações e suas fontes.

Ao trazer a temática para o âmbito da Ciência da Informação é preciso destar que a competência em informação se apresenta na relação entre as fontes de informação e seus usuários, procurando suprimir possíveis lacunas entre ambos, e fazendo com que sejam reconhecidas as unidades de informação (MARTENDAL; SILVA; VITORINO, 2017). O profissional da informação se apresenta no auxílio direto do usuário, e também no desenvolvimento do seu viés pedagógico para conduzir o desenvolvimento da independência na busca, contato e análise das fontes de informação.

Para melhor entendimento a respeito desse tema, faz-se necessário compreender o que é a competência em informação. A American Library Association (ALA) juntamente com a Association of College Research Libraries (ACRL) apresentam a definição de que essa competência corresponde à presença de um "[...] conjunto de habilidades que exige dos indivíduos 'reconhecer quando a informação é necessária e ter a capacidade de localizar, avaliar, e utilizar de forma eficaz a informação necessária' " (2000, p. 2, tradução nossa). Dessa forma, é possível atender a demanda informacional, tanto para necessidades próprias quanto para o auxílio aos usuários.

O avanço tecnológico no ambiente informacional ampliou a concepção da competência em informação. Assim, além de terem habilidades com relação à informação, os profissionais precisam também compreender as novas tecnologias da informação e comunicação. Miranda (2004, p. 118, grifo do autor) enfatiza que "[...] essa competência pode ser expressa pela expertise em lidar com o ciclo informacional, com as tecnologias da informação e com os contextos informacionais". Nessa definição, fica clara a demanda pelo domínio das novas tecnologias, e também na definição apresentada pela ALA e ACRL (2000) que trata da capacidade de localização da informação, exigindo conhecimentos e/ou domínio dos suportes informacionais relativos às novas tecnologias.

A partir das definições apresentadas, compreende-se que o saber utilizar corretamente a informação é um dos objetivos dessa competência. Com relação a isso, Dudziak (2003) ressalta que a educação voltada para o desenvolvimento da competência em informação tem por objetivo a incorporação de comportamentos relacionados à capacidade de investigação; análise crítica; aprendizado de forma independente e contínua. Percebe-se então que não há somente o foco na informação, mas também no desenvolvimento do profissional, já que trata de questões intelectuais.

Além disso, cabe destacar que a competência em informação se apresenta sobre quatro dimensões que são complementares, ou seja, para ser competente em informação é preciso que todas as dimensões estejam presentes. Essas dimensões referem-se à técnica, estética, ética e política, e precisam estar em harmonia na competência e na própria informação para que o desenvolvimento dessa competência se estabeleça nos profissionais (VITORINO; PIANTOLA, 2011).

Para compreender tais dimensões, faz-se necessário tratá-las individualmente. Sendo assim, a dimensão técnica está relacionada ao saber fazer, ou seja, ter as habilidades necessárias para o acesso e uso da informação (OLIVEIRA, 2014). Fica explícito que tal dimensão é necessária para que as demais se desenvolvam já que está relacionada à primeira etapa do processo de desenvolvimento da competência em informação, que é o acesso informacional.

A dimensão ética, assim como a técnica, possui desdobramentos representativos nas demais dimensões. Rios (2008, p. 87, grifo do autor) tratando desse assunto, expõe que a dimensão ética: 
[...] se aponta como dimensão fundante da competência, uma vez que a técnica, a estética e a política ganharão seu significado pleno quando, além de se apoiarem em fundamentos próprios de sua natureza, se guiarem pelos princípios éticos - o respeito, a justiça, a solidariedade.

Dessa forma, o trabalho com as informações deve observar os limites da ética, buscando o equilíbrio entre tais princípios. O acesso informacional deve trazer benefícios tanto para quem dele necessita, quanto para quem está relacionado a ele, por isso a dimensão ética apresenta-se para tratar do bem-estar coletivo.

Com relação à dimensão política Vitorino e Piantola (2011) destacam que ela possui uma vertente pedagógica com relação à cidadania, já que instiga a participação social e capacita para a análise das informações. Do mesmo modo que na ética, percebe-se "[...] a cidadania, como atividade que visa um bem comum, [e portanto] articula-se diretamente com o conceito de política" (VITORINO; PIANTOLA, 2011, p. 107). Essa dimensão, além de reforçar a preocupação com a sociedade, apresenta as diversas possibilidades relativas ao acesso à informação.

Por fim, a dimensão estética está relacionada à sensibilidade e criatividade no uso da informação (VITORINO; PIANTOLA, 2011). Sobre isso, Orelo (2013, p. 140) entende que tal dimensão "[...] resulta na reflexão de suas potencialidades e possibilidades como profissional, capaz de instigar no outro a curiosidade, de estimular o prazer da leitura e do aprendizado e de contribuir para uma sociedade melhor, mais harmoniosa e solidária.", a mesma autora ainda ressalta que a sensibilidade e criatividade dessa dimensão só se concretizam por meio da solidariedade e serenidade.

Após verificar suas características pode-se constatar o significado dessas dimensões. Assim, para ser competente em informação, o profissional utiliza sua sensibilidade visando o bem-estar coletivo e permitindo que seja exercida a cidadania. Dessa forma, um profissional competente em informação, utilizando seus conhecimentos técnicos, consegue:

\footnotetext{
Determinar a extensão da informação que necessita; Acessar a informação necessária de forma eficaz e eficiente; Avaliar criticamente as informações, bem como suas fontes, e incorporar a informação selecionada na sua base do conhecimento; Usar a informação de forma eficaz para realizar um propósito específico; Compreender as questões econômicas, legais e sociais que cercam o uso e acesso da informação de forma ética e legal (ALA; ACRL, 2000, p. 2-3, tradução nossa).
}

Portanto, a competência em informação não se refere somente às habilidades técnicas, há uma preocupação social para com esta atuação. Esse desdobramento correlaciona-se com o acesso à informação, ou seja, com o exercício da cidadania. Farias e Vitorino (2009, p. 11) destacam que a competência em informação "[...] está no cerne do aprendizado ao longo da vida. Ela capacita as pessoas em todos os caminhos da vida, para buscar, avaliar, usar e criar a informação de forma efetiva, para atingirem suas metas pessoais, sociais, ocupacionais e educacionais." Por isso, é necessário que existam profissionais com essa competência para que auxiliem os cidadãos na busca pela informação.

Conforme pode ser observado, a competência em informação, nas respectivas dimensões, caracteriza a atuação dos profissionais que possuem a informação como objeto de trabalho. Para que consiga gerenciar o fluxo informativo o profissional da informação utiliza-se da sua competência em informação para suas próprias necessidades e também para auxiliar aqueles que buscam sua ajuda. Retomando os grupos que formam a competência dos profissionais da informação, tendo como base os grupos do ECIA (tecnologia, gestão, informação, comunicação e outros saberes) e considerando que eles também se apresentam para o contexto brasileiro, verifica-se que neles estão presentes as quatro dimensões da competência em informação (técnica, estética, ética e política). Ou seja, é preciso saber fazer e incorporar a criatividade nas suas rotinas, promover o equilibro de princípios éticos e o exercício da cidadania para que se faça um uso adequado da tecnologia, gestão, informação, comunicação e dos demais saberes que são necessários.

Assim sendo, cabe ressaltar que no próximo tópico é tratada a competência em informação na atuação do profissional arquivista. Nota-se que por ser um profissional que trabalha também com informação tem no cerne de suas atividades, o desenvolvimento das dimensões da competência em informação. Ou seja, utiliza-se da 
técnica, estética, ética e política, para o cuidado com os documentos e informações registradas organicamente, independente do suporte, em todo o seu ciclo de vida, de forma a garantir a recuperação e acesso a elas quando necessário.

\subsection{Competência em informação do arquivista}

Dentre os diversos profissionais que se dedicam à informação, pode-se destacar o arquivista. Faz parte de suas atribuições: atuar na gestão de informações registradas organicamente, ou seja, na produção, classificação, preservação, avaliação, descrição e difusão/disponibilização da informação arquivística, bem como, trabalhar no gerenciamento de unidades de informação. Essas atribuições fazem com que o arquivista possua na essência de sua formação a competência em informação.

Definir esse profissional se faz necessário para a compreensão das suas atribuições. Sendo assim o arquivista é:

\footnotetext{
[...] 1. Especialista encarregado de uma ou de várias funções na gerência de um arquivo. [...] 2. Profissional responsável por analisar e organizar informações registradas (documentos), públicas e privadas, de cunho histórico, governamental, administrativo, científico ou literário, gravações sonoras e filmes (audiovisuais), organizando-os segundo sua origem e outros critérios, e dando-lhes tratamento técnico, armazenando-os em arquivos adequados, permitindo a recuperação eficiente da informação, facilitando sua consulta e evitando que se deteriorem (CUNHA; CAVALCANTI, 2008, p. 24).
}

No Brasil a Lei $n^{\circ} 6.546$, de 04 de julho de 1978, que regulamenta a profissão de arquivista e técnico de arquivo apresenta os critérios para o exercício da profissão e suas atribuições. Dentre as doze atribuições, cabe destacar a presente no inciso II, do $2^{\circ}$ artigo, onde refere-se ao "[...] planejamento, orientação e acompanhamento do processo documental e informativo" (BRASIL, 1978, p. 17). Essa atribuição corrobora com o objetivo da competência em informação, pois apresenta o arquivista como responsável pela gestão documental e informacional culminando no acesso à informação.

O arquivista necessita ser competente em informação, para que consiga atender as atribuições de sua profissão, por isso, cabe apresentar os itens que ressaltam essa característica. Carini (2016, tradução nossa) destaca: saber, interpretar, avaliar, usar, acessar e seguir princípios éticos fazem parte da competência em informação do arquivista. O autor explica que: o saber se caracteriza pelo reconhecimento das fontes; a interpretação diz respeito à análise das informações, questões cronológicas e possíveis faltas de documentos; a avaliação compreende o conhecimento da história e da proveniência que envolvem os documentos; o uso trata de utilizar adequadamente as fontes documentais; o acesso faz referência ao reconhecimento dos documentos e a capacidade de localizá-los; e os princípios éticos correspondem ao utilizar adequadamente as fontes (CARINI, 2016).

Para além desses aspectos da competência em informação pode-se destacar que tal competência está relacionada com as características do perfil desse profissional. Com relação a isso, Bellotto (2006, p. 301) ressalta que as qualidades do arquivista são:

Capacidade de análise e síntese, juntamente com uma aptidão particular para esclarecer situações complexas e ir ao essencial; Habilidade de formular claramente suas idéias, tanto na forma escrita quanto na verbal; Capacidade de julgamento seguro; Aptidão para tomar decisões sobre questões ligadas à memória da sociedade; Abertura às novas tecnologias da informação; Bom senso para tomar resoluções; Adaptação à realidade, às condições de seu tempo e lugar.

O arquivista necessita de informações sobre o contexto que envolve os documentos que irá trabalhar. Somamse a isso outros conhecimentos específicos, para que assim ele seja capaz de fazer suas análises e tomar decisões. Desse modo será possível que a unidade de arquivo cumpra efetivamente com uma de suas principais funções, de disponibilização das informações contidas no acervo sob sua custódia, de forma contextualizada, em consonância com as necessidades de usuários e com o uso de diferentes recursos tecnológicos. 
Com relação ao trabalho do arquivista, cabe destacar que o arquivo necessita, para seu funcionamento, que sejam desenvolvidas as atividades técnicas. Essas atividades envolvem os conhecimentos arquivísticos, por isso:

\footnotetext{
[...] as etapas do processamento técnico de documentos de arquivo assumem destaques nas tarefas organizacionais, especialmente em tarefas em que a eleição de métodos e metodologias a serem desenvolvidas (como identificação, classificação e descrição arquivística) implica, posteriormente, no resultado satisfatório da utilização da informação (FERREIRA; ALMEIDA JÚNIOR, 2013, p.162).
}

A recuperação da informação é pré-requisito para acesso e utilização da informação, por isso o arquivista deve estar atento a esse item. Com isso, ressalta-se a questão do conhecimento e domínio das técnicas, já que elas possibilitam o acesso ao acervo e suas informações.

Das atividades relacionadas à técnica, cabe destacar a avaliação documental arquivística, que analisa e identifica o valor dos documentos e estabelece o ciclo de vida documental, sendo essa uma habilidade do profissional competente em informação. Nesse âmbito, Schellenberg (2006, p. 227) ressalta:

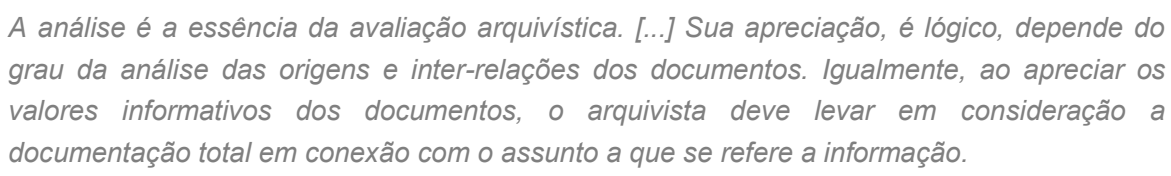

Essa inserção no contexto que envolve o acervo possibilita ao arquivista o desenvolvimento da sua capacidade crítica. Isso pode se refletir na compreensão e também no processo de busca pela informação, o que permite que seja feita uma avaliação das informações e suas fontes. A análise arquivística auxilia tanto nas atividades profissionais, quanto no trabalho de assistência aos usuários da informação.

Destarte, o acesso à informação contida em arquivos depende do arquivista, já que ele conhece o contexto arquivístico e trabalha diretamente com os documentos. Por isso, esse profissional não é somente um custodiador, mas também o responsável por localizar e disponibilizar a informação, garantindo que ela seja acessada sempre que necessário (PETERSON, 2011).

Com relação ao acesso, cabe ainda destacar o impacto das tecnologias nas práticas arquivísticas. Há uma preocupação pelo domínio dessas ferramentas pelos arquivistas, já que essa realidade exige métodos para gerenciar a produção, utilização e conservação de documentos em diferentes suportes (BELLOTTO, 2006). As tecnologias influenciam diretamente no acesso aos documentos, por isso esse profissional precisa estar atento a essas questões.

Além das tecnologias, para a disponibilização da informação é preciso observar as questões éticas. Isso se faz necessário para que não sejam violadas intimidades, questões econômicas, etc., evitando que determinados usos não prejudiquem produtores e demais envolvidos. Por isso, o acesso à informação exige do arquivista:

\footnotetext{
[...] algumas peculiaridades quanto [a] sua conduta, uma vez que, em seu meio, serão encontradas diversas questões de caráter sigiloso, envolvendo o cidadão, a sociedade, ou o Estado, que devem ser preservadas por questões legais (ROCHA; KONRAD, 2013, p.104).
}

Diante disto, pode-se inferir que o conjunto das atribuições do profissional arquivista se "conecta" à competência em informação, à medida que estas incluem habilidades, conhecimentos, comportamentos, valores e atitudes, as quais são parte do processo de produção, armazenamento e acesso a documentos e informações. Ao aproximar os aspectos abordados por Carini (2016) sobre a competência em informação do arquivista com as dimensões da competência em informação que trazem Vitorino e Piantola (2011) nota-se que há um diálogo entre eles. Na dimensão técnica observa-se a inserção do saber e avaliar, tendo em vista que se relacionam com o fazer profissional. Para a dimensão estética há a presença do interpretar, usar e acessar, já que dizem respeito ao uso e estimulo pela busca das fontes informacionais. A dimensão ética se relaciona com o usar, acessar e seguir princípios éticos, pois o uso da informação precisa estar pautado nesses aspectos. Por fim, a dimensão política equipara-se com o acessar, já que ambas referem-se ao acesso à informação. 
Ao definir o arquivista como um profissional competente em informação, pode-se inferir que seu local de trabalho, o arquivo, é propício para o contínuo aprofundamento desta competência. O acesso às fontes documentais, permitem leituras e reconstruções de fatos, além de possibilitar o desenvolvimento da análise crítica e ampliação do conhecimento. Essas questões se aproximam da dimensão política da competência em informação, que se preocupa com a sociedade e a cidadania.

O arquivista, tendo em vista a atuação nos arquivos, desenvolve, além das demais dimensões (técnica, estética e ética), a dimensão política da competência em informação possibilitando o acesso às fontes documentais, já que "a dimensão política diz respeito à participação na construção coletiva da sociedade e ao exercício dos direitos e deveres" (FARIAS; VITORINO, 2009, p. 9). É sobre esta dimensão que se dedica o item a seguir.

\section{Dimensão política da competência em informação do arquivista}

O acesso aos arquivos permite o contato com informações governamentais e culturais, por isso é admissível uma concentração de esforços para desenvolvimento de ações sociais e pedagógicas nessas instituições. Além das vantagens para os usuários desse tipo de ambiente, destaca-se a relação do arquivo com o arquivista para desenvolvimento da dimensão política da competência em informação desse profissional, que é o responsável pelo acesso às fontes informacionais arquivísticas.

O acesso à informação é imperativo, pois possibilita reconhecer aspectos contextuais e permite o acompanhamento de decisões, por exemplo, na esfera governamental. Isso gera um empoderamento social para identificação e discussão de questões que Ihes parecem importantes. Essa postura é a mesma adotada na dimensão política, que se caracteriza pelo exercício da cidadania, permitindo a participação social e capacitando para que o cidadão consiga analisar além do que lhe é apresentado (VITORINO; PIANTOLA, 2011).

Então, é necessário que haja uma preocupação com que os usuários saibam fazer os questionamentos de forma a proporcionar a obtenção da informação necessária, para que seja possível a análise delas suscitando novos conhecimentos. Dudziak (2008, p. 47) ressalta que quando "relacionada à cidadania, a competência em informação vai muito além da busca, organização e uso das informações pois significa saber o porquê do uso de determinada informação, considerando implicações ideológicas, políticas e ambientais". Para fazer essas relações, os documentos arquivísticos aparecem como matéria-prima ou "vozes" nas interlocuções para a reconstrução e compreensão situacional.

Após verificar o que se propõe a dimensão política da competência em informação, cabe discorrer que os arquivos, são locais para aprendizagem, bem como de guarda documental. Destaca-se que o termo arquivo pode ser entendido de diversas formas, porém nesse estudo adota-se como instituição em que estão armazenados os documentos. Nesse sentido, segundo o Dicionário Brasileiro de Terminologia Arquivística, o arquivo é um "[...] Conjunto de documentos produzidos e acumulados [...]. Instituição ou serviço que tem por finalidade a custódia, o processamento técnico, a conservação e o acesso a documentos" (ARQUIVO NACIONAL, 2005, p. 27, grifo do autor). Optou-se por essa definição, pois envolve a instituição onde se desenvolve o trabalho arquivístico com o objetivo de permitir o acesso informacional.

Conforme já mencionado, os arquivos são constituídos de fontes orgânicas de informação, produzidas em atos contínuos da vida de uma pessoa ou instituição, pública ou privada. Os usuários desse tipo de informação podem explorar essas fontes e desenvolver seus conhecimentos com o auxílio delas. Além disso, Fratini (2009, p. 6) ressalta que,

\footnotetext{
[...] é grande o aprendizado que se pode obter a partir de um trabalho com documentos de arquivo escritos, em termos de construção de saberes linguísticos, históricos e de cidadania, já que [...] envolvem questões de direitos e deveres entre governo e cidadãos.
}

Para que seja possível o aprendizado por meio dos documentos, é necessária a gestão documental. Somente assim será possível conhecer e acessar as informações contidas em determinado acervo. O direcionamento dos esforços arquivísticos para questões técnicas tem por objetivo também: 
depurando critérios de avaliação destas massas documentais visando decidir o destino e a temporalidade das séries documentais (SMIT, 2003, p. 75, grifo do autor).

As fontes arquivísticas além de possibilitarem a ampliação do conhecimento sobre determinada área de interesse, podem ser utilizadas como garantia da cidadania. O arquivo possui uma função educativa e social, já que no seu acervo podem conter informações dessa natureza. Cabe ressaltar que não somente aos arquivos públicos governamentais, mas também os privados, também chamados de pessoais, apresentam esse viés educativo e social. Isso pode ocorrer quando o material disponível no acervo apresentar contribuições tanto para a sociedade quanto para a ciência, levando em consideração a privacidade e justificando as restrições de acesso quando necessário (BELLOTTO, 2006).

Para que o trabalho com fontes documentais possa ser executado, é preciso promover o acesso. Sob esta perspectiva, estão especialmente os documentos que constituírem o arquivo permanente, cuja função que também informa, indicia atos e fatos jurídicos, administrativos e funcionais, todavia ocorridos em tempos passados. Ou seja, são documentos que não estão mais em plenitude de seus valores legais, já houve a prescrição jurídica, contudo, a informação é de interesse histórico, cultural, educativo, de memória institucional e, ou pessoal, seja em contexto marco ou micro. É a fase de vida documental arquivística em que:

[...] melhor pode desenhar seus contornos sociais, dando-lhe projeção na comunidade, trazendo-lhe a necessária dimensão popular e cultural que reforça e mantém o seu objetivo primeiro. Trata-se de seus serviços editoriais, de difusão cultural e de assistência educativa (BELLOTTO, 2006, p. 227).

No que tange às atividades que promovem a difusão cultural e educativa, estas permitem uma aproximação de usuários com as instituições arquivísticas. Ou seja, uma das atribuições do arquivista constitui-se em mostrar que o arquivo é o espaço promotor de uma educação cultural, o qual permite a ampliação das possibilidades de usos deste espaço e também a construção de conhecimentos nos seus usuários.

Apesar de relacionar o arquivo com apenas uma das dimensões da competência em informação, é importante destacar que o arquivista pode desenvolver tal competência de forma completa neste ambiente, que é uma unidade de informação. O arquivista pode exercer sua competência em informação e estimular no usuário o desenvolvimento dela por meio dos processos de busca, análise e interpretação dos documentos. Desenvolver a competência em informação nos usuários é permitir que eles utilizem de forma eficaz as fontes documentais. Assim o arquivista e o arquivo aplicam, por meio dos seus serviços, a função de ensino a partir do capital informativo que tem sob sua custódia (ARAÚJO, 2014).

Faz-se interessante estreitar essa relação de arquivo e usuários desde cedo. O estímulo ao uso de fontes documentais é uma das formas de fazer essa aproximação, por isso:

\footnotetext{
[...] el uso pedagógico del documento em el mundo de la enseñanza es el punto de arranque de uma acción que se irradia um ámbito muy amplio y de uma influencia educativa capital. Uma buena forma de despertar elinterés de los alunos por lá historia huyendo de la abstracción de los manuales es por nerlos em contacto com la materia prima de la investigación histórica [...] (FUGUERAS, 2003, p. 170).
}

A ação pedagógica pode ocorrer em qualquer etapa na educação formal (da educação infantil ao ensino superior de graduação e pós-graduação), e informal, já que os documentos são fontes a serem pesquisadas para diferentes fins, inclusive lúdico, recreativo e cultural. Ou seja, o arquivista além de auxiliar o usuário na busca por informações, cabe a ele também ensina-lo a desenvolver sua competência em informação, para que assim desenvolva sua independência em aspectos informacionais.

Pode-se perceber que o arquivo é um local que evidencia a dimensão política da competência em informação, permitindo a ampliação do conhecimento histórico e social, já que custodia informações indiciárias de diferentes contextos. Dessa forma, a dimensão política da competência em informação do arquivista se reflete juntamente com a função educativa e social do arquivo ressaltando para a necessidade do acesso às fontes documentais, e mais do que isso, da análise e estudo delas. 


\section{Considerações finais}

O acesso à informação é um item necessário para a produção de conhecimento e exercício da cidadania. Sendo assim, os profissionais que trabalham de forma intensiva com a informação necessitam desenvolver a competência profissional e a competência em informação. Isso exige conhecimentos técnicos, tecnológicos, sociais e de comunicação.

Por meio da presente pesquisa bibliográfica, foi possível perceber que os profissionais da informação podem vir de diferentes formações e com conhecimentos diversos, o que lhes dá a característica comum é o trabalho com a informação. Por isso mesmo, não há um conjunto determinante da competência desses profissionais, porém a competência em informação precisa necessariamente ser desenvolvida na formação basilar, na formação continuada, e também na prática diária de trabalho (a experiência profissional). Por meio da análise da literatura pode-se observar que a competência do profissional da informação remete, e, por isso se relaciona, com a competência em informação e suas dimensões.

A competência em informação possibilita uma autonomia com relação à busca e análise da informação. Ela traz consigo benefícios tanto para o profissional, quanto para o ambiente de trabalho em que ele está inserido. Além disso, é uma competência formativa e qualitativa para o exercício profissional e da cidadania, já que desenvolve habilidades para localizar e avaliar as informações e, se evidencia, em última instância, na dimensão política desta competência.

Com relação ao arquivista, observou-se que é competente em informação tendo em vista que é um profissional que trabalha com a informação orgânica e, por isso desenvolve a competência dos profissionais da informação, sendo: informação, tecnologia, comunicação, gestão e demais saberes. Assim, a competência em informação desse profissional está em consonância com os grupos de competência dos profissionais da informação que são definidos pelo ECIA (2005). Nos aspectos informacionais o arquivista segue as diretrizes do saber, interpretar, avaliar, acessar e dos princípios éticos. Com relação aos aspectos tecnológicos destacam-se o saber usar e o atendimento dos princípios éticos. A comunicação está direcionada ao usar a informação. E na gestão tem-se implícito: saber; avaliar; usar; acessar; e seguir a ética.

Além disso, por meio das suas atividades profissionais e também do ambiente em que se insere pode-se verificar que ambos auxiliam o desenvolvimento da competência em informação nas suas quatro dimensões apresentadas por Vitorino e Piantola (2011). A técnica, estética, ética e política estão refletidas nas atividades e perfil do arquivista. O fazer arquivístico requer tais dimensões da competência em informação para o desenvolvimento do ambiente da informação arquivística, e também para as ações pedagógicas que instigam o desenvolvimento da competência em informação do usuário.

Ao tratar do desenvolvimento da competência em informação, cabe ressaltar que o arquivo é um ambiente propício à dimensão política, pois conecta-se sobremaneira com as atribuições do arquivista e, por consequência, com os objetivos da instituição arquivística, ou seja, permitir o acesso aos documentos e disseminar informações disponíveis nos seus acervos e também informações a respeito da gestão documental arquivística. Sendo assim, as ações pedagógicas e culturais podem ser utilizadas como forma de desenvolver as atividades arquivísticas e contribui para a dimensão política da competência em informação no arquivista.

Como limitação do estudo cita-se a carência de análise teórica aprofundada exclusivamente sobre cada uma das dimensões da competência em informação para com o arquivista. Além disso, não há um diálogo entre teoria e prática, ou seja, o contato com arquivistas para verificar na sua atuação como se aplica a competência em informação. No entanto, o presente estudo atendeu seu objetivo de identificar a competência em informação do arquivista, evidenciando por meio da teoria a sua presença na caracterização profissional, demonstrando que o arquivista vai além do custodiador de documentos. A partir do que foi apresentado neste trabalho, na perspectiva que se trata de uma abordagem qualitativa, exploratória e bibliográfica sobre a temática, pode-se realizar outras pesquisas que se ocupem de investigar as ações desenvolvidas por arquivistas e que evidenciam a dimensão política da competência em informação nesta profissão. E, conforme mencionado nas limitações do estudo, também se pode empreender investigações sobre as demais dimensões desta competência, de modo a demonstrar as possíveis ligações destas com a prática arquivística. 


\section{Referências}

AMERICAN LIBRARY ASSOCIATION (ALA); ASSOCIATION OF COLLEGE AND RESEARCH LIBRARIES (ACRL). Information literacy competency stardards for higher education. Illinois: 2000. Disponível em: https://alair.ala.org/bitstream/handle/11213/7668/ACRL\%20Information\%20Literacy\%20Competency\%20Standards\%20for\%20 Higher\%20Education.pdf?sequence=1\&isAllowed=y. Acesso em: 25 abr. 2016.

ARAÚJO, Carlos Alberto Ávila. Arquivologia, biblioteconomia, museologia e ciência da informação: o diálogo possível. Brasília: Briquet de Lemos, 2014.

ARQUIVO NACIONAL (Brasil). Dicionário brasileiro de terminologia arquivística. Rio de Janeiro: Arquivo Nacional, 2005. Disponível em: http://www.arquivonacional.gov.br/images/pdf/Dicion Term Arquiv.pdf. Acesso em: 02 mai. 2016.

BELLOTTO, Heloísa Liberalli. Arquivos Permanentes: Tratamento documental. 4ª ed. Rio de Janeiro: FGV, 2006.

BELLUZZO, Regina Célia Baptista. As competências do profissional da informação nas organizações contemporâneas Revista Brasileira de Biblioteconomia e Documentação, São Paulo, v. 7, n 1, p. 58-73, jan./jun. 2011. Disponível em: https://rbbd.febab.org.br/rbbd/article/view/180/186. Acesso em: 04 abr. 2016.

BORKO, Harold. Information Science: what is it? American Documentation, v. 19, n. 1, p. 3-5, jan. 1968. Disponível em https://www. marilia.unesp.br/Home/Instituicao/Docentes/EdbertoFerneda/k---artigo-01.pdf. Acesso em: 15 dez. 2018

BRASIL. Lei $n^{\circ}$ 6.546, de 04 de julho de 1978. Dispõe sobre a regulamentação das profissões de Arquivista e de Técnico de Arquivo, e dá outras providências. In: Coletânea da Legislação Arquivística Brasileira e Correlata. Rio de Janeiro: Arquivo Nacional, p. 17-18, dez.2017. Disponível em:

http://conarq.arquivonacional.gov.br/images/coletanea/dez 2017/CONARQ legarquivos dezembro 2017 PDF2.pdf. Acesso em: 15 dez. 2018.

CARINI, Peter. Information literacy for archives and special collections: defining outcomes. Libraries and the Academy, Baltimore, v. 16, $\mathrm{n}^{\circ}$ 1, p. 193-208, 2016. Disponível em: https://www.press.jhu.edu/journals/portal libraries and the academy/portal pre print/articles/16.1carini.pdf. Acesso em: 02 mai. 2016.

COOPER, Donald R.; SCHINDLER, Pâmela S. Métodos de Pesquisa em Administração. 12 a ed. Porto Alegre: AMGH Editora Ltda, 2016.

CORREIA, Zita P. Referencial das competências dos profissionais europeus de informação e documentação: da génese às perspectivas de futuro. Cadernos BAD: Revista da Associação Portuguesa de Bibliotecários, Arquivistas e Documentalistas, Lisboa, $n^{\circ}$ 1, p. 8-21, 2003. Disponível em: http://www.bad.pt/publicacoes/index.php/cadernos/article/view/853/852. Acesso em: $21 \mathrm{abr} .2016$

CUNHA, Murilo Bastos da; CAVALCANTI, Cordélia Robalinho de Oliveira. Dicionário de biblioteconomia e arquivologia. Brasília: Briquet de Lemos, 2008

DUDZIAK, Elisabeth Adriana. Os faróis da sociedade de informação: uma análise crítica sobre a situação da competência em informação no Brasil. Informação \& Sociedade, João Pessoa, v. 18, n² 2, p. 41-53, mai./ago. 2008. Disponível em: http://www. periodicos.ufpb.br/ojs/index.php/ies/article/view/1704/2109. Acesso em: 10 mai. 2016.

DUDZIAK, Elisabeth Adriana. Information literacy: princípios, filosofia e prática. Ciência da Informação, Brasília, v. 32, n. 1, p. 23-35, jan./abr. 2003. Disponível em: http://www.scielo.br/pdf/ci/v32n1/15970.pdf. Acesso em: 31 mar. 2016.

EUROPEAN COUNCIL OF INFORMATION ASSOCIATION (ECIA). Euro-Referêncial I-D, Lisboa: INCITE, 2005. Disponível em: https://www.eseig.ipp.pt/documentos/doc noticias/EuroReferencial P.pdf. Acesso em: 07 mai. 2016.

FARIA, Sueli et al. Competências do profissional da informação: uma reflexão a partir da Classificação Brasileira de Ocupações. Ciência da Informação, Brasília, v. 34, n² 2, p. 26-33, mai./ago. 2005. Disponível em: http://www.scielo.br/pdf/ci/v34n2/28552. Acesso em: 22 abr. 2016.

FARIAS, Christianne Martins; VITORINO, Elizete Vieira. Competência informacional e dimensões da competência do bibliotecário no contexto escolar. Perspectivas em Ciência da Informação, Belo Horizonte, v. 14, n 2, p. 2-16, mai/ago. 2009. Disponível em: http://portaldeperiodicos.eci.ufmg.br/index.php/pci/article/view/699/575. Acesso em: 07 mai. 2016.

FERREIRA, Danielle Thiago. Profissional da informação: perfil de habilidades demandadas pelo mercado de trabalho. Ciência da Informação, Brasília, v. 32, n 1, p. 42-49, jan./abr. 2003. Disponível em: http://revista.ibict.br/ciinf/article/view/1018/1073. Acesso em: 07 mai. 2016.

FERREIRA, Letícia Elaine; ALMEIDA JÚNIOR, Oswaldo Francisco de. A mediação da informação no âmbito da arquivística Perspectivas em Ciência da Informação, Belo Horizonte, v. 18, n 1, p. 158-167, jan./mar. 2013. Disponível em: http://portaldeperiodicos.eci.ufmg.br/index.php/pci/article/view/1270/1111. Acesso em: 09 mai. 2016.

FRATINI, Renata. Educação patrimonial em arquivos. Histórica - Revista Eletrônica do Arquivo Público do Estado de São Paulo, São Paulo, n³4, p. 1-11, 2009. Disponível em:

http://www.historica.arquivoestado.sp.gov.br/materias/anteriores/edicao34/materia05/texto05.pdf. Acesso em: 03 mai. 2016. 
FUGUERAS, Ramon Alberch. Los archivos, entre la memoria histórica y la sociedad del conocimento. Barcelona: UOC, 2003.

JARDIM, José Maria. A produção do conhecimento arquivístico: perspectivas informacionais internacionais e o caso brasileiro (1990-1995). Ciência da Informação, Brasília, v. 27, n 3, 1998. Disponível em: http://revista.ibict.br/ciinf/article/view/777/806. Acesso em: 06 mai. 2016.

LIMA, Telma Cristiane Sasso de; MIOTO, Regina Célia Tamaso. Procedimentos metodológicos na construção do conhecimento científico: a pesquisa bibliográfica. Revista Katálysis, Florianópolis, v. 10, n. esp., p. 37-45, 2007. Disponível em: https://periodicos.ufsc.br/index.php/katalysis/article/view/S1414-49802007000300004. Acesso em: 07 out. 2016.

MALHOTRA, Naresh. Pesquisa de Marketing: uma orientação aplicada. 6. ed. Porto Alegre: Bookman, 2012.

MARTENDAL, Fernanda Frasson; SILVA, Eva Cristina Leite da; VITORINO; Elizete Veira; Diálogo entre as dimensões da competência em informação e os cursos de graduação em Arquivologia do Sul do Brasil. Em questão, Porto Alegre, v. 23, n. 3 , p. 53-78, set./dez. 2017. Disponível em: https://seer.ufrgs.br/EmQuestao/article/view/69952/41370. Acesso em: 15 dez. 2018.

MIRANDA, Silvânia Vieira. Identificando competências informacionais. Ciência da Informação, Brasília, v. 33, n 2, p. 112-122, maio/ago. 2004. Disponível em: http://revista.ibict.br/ciinf/article/view/1053/1132. Acesso em: 22 abr. 2016.

MINISTÉRIO DO TRABALHO E EMPREGO (MTE). Classificação Brasileira de Ocupações. Competências pessoais. Brasília, [2016?]. Online. Disponível em: http://www.mtecbo.gov.br/cbosite/pages/pesquisas/ResultadoFamiliaDescricao.jsf. Acesso em: 07 mai. 2016.

OLIVEIRA, Alexandre Pedro. A dimensão técnica da competência informacional: estudo com bibliotecários de referência das bibliotecas universitárias da grande Florianópolis, SC. 2014. 205 f. Dissertação (Mestrado em Ciência da Informação) Universidade Federal de Santa Catarina, Florianópolis, 2014. Disponível em: http://tede.ufsc.br/teses/PCIN0105-D.pdf. Acesso em: 14 jul. 2017.

ORELO, Eliane Rodrigues Mota. A dimensão estética (sensível) da competência informacional. 2013. 197 f. Dissertação (Mestrado em Ciência da Informação) - Universidade Federal de Santa Catarina, Florianópolis, 2013. Disponível em: https://repositorio.ufsc.br/bitstream/handle/123456789/122792/323984. pdf?sequence=1\&isAllowed=y. Acesso em: 05 mai. 2016.

PETERSON, Trudy Huskamp. Um projeto sobre acesso. Acervo Revista do Arquivo Nacional, Rio de Janeiro, v. 24, $n^{\circ} 1$, p. 217-232, jan./jun. 2011. Disponível em: http://revista.arquivonacional.gov.br/index.php/revistaacervo/article/view/380/380. Acesso em: 09 mai. 2016.

PRIMI, Ricardo et al. Competências e habilidades cognitivas: diferentes definições dos mesmos construtos. Psicologia: Teoria e Pesquisa, Brasília, v. 17, n² 2, p. 151-159, mai./ago. 2001. Disponível em: http://www.scielo.br/pdf/ptp/v17n2/7875. Acesso em: 08 jul. 2016.

RICHARDSON, Roberto Jarry; PERES, José Augusto de Souza. Pesquisa social: métodos e técnicas. $3^{a}$ ed. São Paulo: Atlas, 2012.

RIOS, Terezinha Azerêdo. A presença da filosofia e da ética no contexto profissional. Organicom Revista Brasileira de Comunicação Organizacional e Relações Públicas, São Paulo, v. 5, nº 8, p. 79-88, jan./jun. 2008. Disponível em: http://www.revistas.usp.br/organicom/article/view/138969/134317. Acesso em: 14 jul. 2016

ROCHA, Isadora Martins Marques da; KONRAD, Glaucia Vieira Ramos. A conduta do arquivista frete à lei de acesso à informação. Informação Arquivística, Rio de Janeiro, v. 2, n² 2, p. 103-123, jul./dez. 2013. Disponível em http://www. aaeri.org.br/ojs/index.php/informacaoarquivistica/article/view/47/26. Acesso em: 09 mai. 2016.

SCHELLENBERG, Theodore. R. Arquivos modernos: princípios e técnicas. 6. ed. Rio de Janeiro: Editora FGV, 2006.

SILVA, Armando Malheiro da; RIBEIRO, Fernanda. Formação, perfil e competências do profissional da Informação. Congresso Nacional de Bibliotecários, Arquivistas e Documentalistas, Estoril, $n^{\circ} 8$, maio/2004. Disponível em: http://www.bad.pt/publicacoes/index.php/congressosbad/article/view/622/619. Acesso em: 04 abr. 2016.

SMIT, Johanna W. Arquivologia/Biblioteconomia: interfaces das ciências da informação. Informação \& Informação, Londrina, v. 8, n² 2, p. 66-78, jul./dez. 2003. Disponível em: http://www.uel.br/revistas/uel/index.php/informacao/article/viewFile/1713/1464. Acesso em: 03 mai. 2016

TARAPANOFF, Kira; SUAIDEN, Emir; OLIVEIRA, Cecília Leite. Funções sociais e oportunidades para profissionais da informação. DataGamaZero: Revista de Ciência da Informação, v. 3, $n^{\circ}$ 5, p. 1-11, out./2002. Disponível em: http://ridi.ibict.br/bitstream/123456789/256/1/CECILIADTZ2002.pdf. Acesso em: 02 mai. 2016.

VITORINO, Elizete Vieira. PIANTOLA, Daniela. Dimensões da competência informacional (2). Ciência da Informação, Brasília, v. 40, n 1, p. 99-110, jan./abr. 2011. Disponível em: http://www.scielo.br/pdf/ci/v40n1/a08v40n1. pdf. Acesso em: 02 mai. 2016. 


\section{Dados dos autores}

\section{Renata Ventura}

Mestra em Ciência da Informação pelo Programa de Pós-Graduação em Ciência da Informação (PGCIN) e Bacharel em Arquivologia pela Universidade Federal de Santa Catarina (UFSC).

ventura_r@hotmail.com

\section{Eva Cristina Leite da Silva}

Doutora e Mestre em Educação pela Universidade Estadual de Campinas (UNICAMP). Professora no Departamento de Ciência da Informação (CIN), do Centro de Ciências da Educação (CED) da Universidade Federal de Santa Catarina (UFSC). Atua nos Cursos de Graduação em Arquivologia, Biblioteconomia e Ciência da Informação, e no Programa de Pós-Graduação em Ciência da Informação (PGCIN).

eva.cristina@ufsc.br

\section{Elizete Vieira Vitorino}

Doutora e Mestre em Engenharia de Produção pela Universidade Federal de Santa Catarina (UFSC). Professora no Departamento de Ciência da Informação (CIN), do Centro de Ciências da Educação (CED) da Universidade Federal de Santa Catarina (UFSC). Atua nos Cursos de Graduação em Arquivologia, Biblioteconomia e Ciência da Informação, e no Programa de Pós-Graduação em Ciência da Informação (PGCIN).

elizete.vitorino@ufsc.br

Recebido - Received: 2016-12-23

Aceitado - Accepted: 2018-12-11

\section{$(\mathrm{cc}) \mathrm{EY}$}

This work is licensed under a Creative Commons Attribution 4.0

United States License.

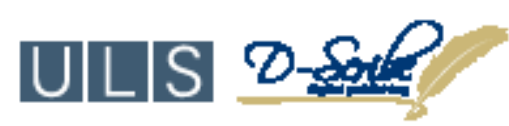

This journal is published by the University Library System of the University of Pittsburgh as part of its D-Scribe Digital Publishing Program and is cosponsored by the University of Pittsburgh Press. 